\title{
Teologia e experiência Uma abordagem sobre a centralidade da experiência para a teologia
}

Renato da Silva Machado

\section{Resumo}

A teologia pauta-se na experiência de Deus. Deus se autocomunica, fazendo-se acessível ao ser humano enquanto criatura capaz de Deus. Este ser humano é um ser transcendental, que se realiza na abertura a este Outro. Da tentativa de exprimir esta experiência surge a teologia. Ela é uma palavra sobre o Mistério que se autocomunicou a nós, esforço dizer algo sobre aquilo que é inexprimível e inesgotável. A teologia, no entanto, muitas vezes tematizada de modo a-histórico, desprovida de significado para as pessoas e restringindo-se a doutrinas desconexas com a vida concreta. Uma linguagem abstrata, teórica e descontextualizada, que não diz nada para o homem moderno nem mesmo quando este ainda se afirma cristão. Este tipo de teologia faz a Igreja cair num descrédito, limitando sua reflexão e atuação à "sacristia"; sem influxo na sociedade e na cultura.

Pretenderemos aqui, em primeiro lugar, apontar a importância da experiência para que a teologia tenha a sua pertinência e relevância no tempo presente. Em segundo lugar, verificaremos a questão da experiência como o fundamento, a raiz da teologia. Por fim, mostraremos que a experiência não é somente o fundamento da teologia mas também o seu destino, uma vez que ela deve ser oportunidade para novas experiências com o Mistério.

Palavras-chave: Experiência, Teologia, Mistério. 


\begin{abstract}
The theology is based on the experience of God. God self communicates, thus making himself accessible to the human being as a creature capable of God. The human being is a transcendent being, Who finds a pupose for his existence as he opens himself to this Other. Theology arises as na attempt to express such experience. It is a word about the Mystery that has self comunicated with us, effort to say something about what is ineffable and inexhaustible. A non-historical, meaningless, and unconcrete theology, though. Na abstract, theoretical and decontextualized language that says nothing to modern man even when he still says he is a Christian. This kind of theology makes the Church hard to believe, as it is restrited to the "sacristy" and exerts no influence on society or culture.

First of all, we intend to point out the importance of experience so that theology fits and is relevant at the present time. Secondly, we will verify the matter of experience as the foundation, the root of theology. Finally, we will show that the experience is not only the foundation of theology, but also its destination, since it must become an opportunity for new experiences with the Mystery.
\end{abstract}

Keywords: Experience, Theology, Mystery.

\title{
O advento da experiência
}

Vivemos numa época da experiência. A modernidade que prometia com a razão dar conta da realidade entra em crise e emerge então uma nova época chamada por muitos de pós modernidade. ${ }^{1}$ Nesta o conhecimento por experiência tem sua primazia frente ao científico. Se na modernidade a razão era o elemento chave de compreensão da realidade, na pós modernidade deu o seu lugar à experiência. Não que a experiência abandone a razão, a racionalidade se faz presente também na experiência, porém não a determina. Experiência não se trata apenas da dinâmica de uma parte do ser humano mas refere-se ao ser humano por inteiro, com toda sua inteligência, vontade, sentimentos, imaginação corporeidade. ${ }^{2}$ Experiência que envolve, neste sentido, toda a existência do ser humano e não apenas uma dimensão deste.

\footnotetext{
${ }^{1}$ Sobre a crise da modernidade ver Cf. CAPRA, F. O ponto de mutação. São Paulo: Cultriz, s/d. pp. 19-225.

${ }^{2}$ MIRANDA, Mario de França. Inculturação da fé. São Paulo: Loyola, 2001, p. 67.
} 
O conhecimento por experiência é de certo modo imediato pois é o sujeito mesmo que realiza a experiência. Diz-se desta forma que a experiência é imediata porque não acontece através da atividade discursiva da inteligência ou mesmo por reflexão posterior nem ainda por acatamento da autoridade de terceiros ou tradição histórica, mas pela percepção do sujeito que a realiza. ${ }^{3}$ Seu conhecimento não provém de fora como que algo já experimentado por outros e que cabe a ele acatar, mas a imediatez própria da experiência diz respeito à relação que o ser humano vai ter com este outro que lhe vem, não se trata de algo que lhe é imposto mas algo que ele experimenta validando ou não a experiência dos outros e as suas próprias anteriores a sua experiência atual.

Pensadores questionam sobre o acesso a verdade na experiência, refletem até que ponto uma experiência traz consigo a verdade do experimentado, até que ponto ela não é proveniente do próprio sujeito, da história, de ideologias, da linguagem. ${ }^{4}$ Estas afirmações não invalidam radicalmente a realidade da verdade da experiência mas nos fazem perceber que toda experiência humana é mediada, ou seja se serve da história, da linguagem, de outras experiências realizadas. Sempre pressupõe um "quadro de interpretação" que a determina. ${ }^{5}$ Trata-se do horizonte apreendido pelo ser humano a partir de suas diversas experiências anteriores e ainda do horizonte maior no qual ele se apresenta inserido. $\mathrm{O}$ sujeito que faz a experiência, a realiza trazendo toda a sua existência, sua cultura, linguagem e experiências outras diversas realizadas por ele.

\section{Experiência da fé na pós modernidade}

No âmbito da religiosidade percebemos a força que a experiência subjetiva possui em nossos dias. Observamos o fenômeno da chamada "bricolagem religiosa", ${ }_{6}^{6}$ processo de apropriação de elementos numa nova configuração religiosa elaborado pelo sujeito. Se por um lado se enxerga o encolhimento da religião seja em relação à proporção de adeptos, seja no modo de influência na política e na vida social, por outro lado se vê a proliferação da religiosidade através das chamadas religiões "a la carte", de uma religiosidade "flutuante",

\footnotetext{
${ }^{3}$ Id., A Salvação de Jesus Cristo: a doutrina da graça. São Paulo: Edições Loyola, 2004, p. 180.

${ }^{4}$ Sobre isto verificar em MIRANDA, Mario de França. Inculturação da fé. p. 67-68.

${ }^{5}$ SCHILLEBEECKX, Edward. História humana: revelação de Deus. São Paulo: Paulus, 2003. pp. 34-44.

${ }^{6}$ HERVIEU-LEGER, Danièle. O peregrino e o convertido: a religião em movimento. Petrópolis, RJ: Vozes, 2008. p. 22.
} 
de crenças "relativas", de novas elaborações sincréticas... Com isto transparece que o crer, na sociedade moderna, está desassociado do ser religioso: Não é o fato de "crer em Deus", como se pensou no passado, que torna o ser humano religioso. É possível "crer em Deus" de maneira não religiosa, através de uma experiência mística, iluminação interior, contemplação estética ou engajamento ético sem filiação ou adesão a um sistema religioso. A crença só é religiosa quando o crente coloca diante de si a lógica do desenvolvimento que o leva a crer naquilo que crê. ${ }^{7}$ Ela contudo pode existir independente de um vínculo religioso.

A religiosidade é construída nesta nova época a partir do sujeito que faz a experiência transcendental e por ele. Há uma diferenciação entre a pertença confessional e a aceitação da confissão religiosa da mesma instituição. Muitos se declaram pertencer a determinado seguimento religioso, no entanto, acreditando em crenças diversas e até mesmo opostas a confissão de seu seguimento. Podemos ter reservas em relação a esta nova religiosidade que se apresenta, mas havemos de concordar que ela traz em relevo algo que é fundamental no cristianismo - a experiência que a pessoa faz em primeira pessoa do Mistério de Deus em Cristo. A experiência de Deus que é objetiva, ou seja, é experiência de Deus mesmo que vem ao nosso encontro, que não é fruto da imaginação humana, mas uma realidade em si mesma, é também subjetiva uma vez que quem faz esta experiência é o ser humano dotado de liberdade e consciência, que se abre a percepção do Mistério de Deus, deixando-se envolver por Ele. Esta dimensão da subjetividade muitas vezes foi deixada de lado pela teologia muitas vezes racional e pragmática por demais que obscureceu a dimensão subjetiva da fé e da religião.

O presente quadro de bricolagem religiosa evidencia a necessidade de uma preocupação com o indivíduo religioso. Perceber que ele é capaz de fazer um encontro com Deus de modo pessoal, intima, que pode ser favorecido pela comunidade eclesial que por sua vez não pode realizá-la no lugar do indivíduo. Apresenta-se deste modo a necessidade na comunidade eclesial, de fazer dos cristãos verdadeiros convertidos, místicos, pessoas que fizeram um encontro com Cristo capaz de subverter as suas vidas, alcançando a Igreja a sua missão de ser neste mundo sacramento de Cristo. Percebe-se que não é mais possível ser cristão (se é que possamos dizer que algum diz já foi possível o ser no sentido do termo) apenas por herança dos antepassados, por forma-

${ }^{7}$ Ibid., pp. 26-27. 
lidade, mas somente a partir da própria convicção de fé elaborada a partir de uma experiência pessoal do sujeito com o Deus da salvação. ${ }^{8}$ Fica desta forma, mais latente a constatação e/ou convite provocador de Karl Rahner: "o cristão do futuro, ou será místico ou não será cristão"9. Num mundo em que ressoam tantas propostas, se aquele que se diz cristão não faz uma experiência mística com Deus no sentido de se encontrar diante do Mistério Absoluto que dá sentido a sua existência fatalmente abandonará a fé e sua prática mesmo que racionalmente esta possa ter a sua credibilidade.

\section{Experiência e discurso teológico}

Se a questão da experiência é decisiva no período hodierno, é mister verificarmos se ela tem algo a dizer a teologia, se possui relação e se faz alguma provocação a esta.

A teologia é vista por muitos hoje com suspeita por ter se cristalizado por um bom período, numa objetividade clássica que a tornou "estranha ao seu próprio tempo, não incisiva para a vida nem relevante para a história" ${ }^{10}$. Muitas vezes tematizada de modo a-histórico, ou seja, desprovida de significado para os homens e mulheres, restringindo-se a um corpo de doutrinas desconexas com a vida concreta, um conjunto de fórmulas elaboradas por um grupo seleto de cristãos, a teologia se reduziu a uma mera repetição de fórmulas desconexas da vida concreta das pessoas e culturas. Fórmulas que poderiam ter até uma razão de ser em determinados momentos históricos, porém que devem ser repensadas e reformuladas em cada época para que continuem a transmitir a vivacidade da experiência.

Gustavo Gutierrez nos lembra que a teologia pensada como inteligência da mera afirmação de verdades necessita ser hoje um compromisso, uma atitude global em favor da vida, para que possa ser novamente relevante. ${ }^{11}$ Trata-se de um olhar atento a realidade concreta do povo, percebendo as maravilhas que são realizadas como também as dificuldades, lutas e desafios do

\footnotetext{
${ }^{8}$ Neste sentido pode-se verificar nas paróquias a diminuição do índice daqueles que vem pedir os sacramentos do batismo e eucaristia para os seus filhos ou ainda o do matrimonio para si, outrora tão procurados pela massa católica.

${ }^{9}$ RAHNER, Karl. O Cristão do Futuro. São Paulo: Cristã Novo Século, 2004. p. 78.

${ }^{10}$ FORTE, Bruno. A teologia como companhia, memória e profecia. Introdução ao sentido e ao método da teologia como história. São Paulo: Paulinas, 1991. p. 180.

${ }^{11}$ GUTIÉRREZ, Gustavo. Falar de Deus a partir do sofrimento do inocente: uma reflexão sobre o livro de Jó. Petrópolis, RJ: Vozes, 1987, p. 166.
} 
povo lançando luzes de consolação e esperança. Uma linguagem abstrata, teórica e descontextualizada, que não diz nada para o ser humano de hoje nem mesmo quando este ainda se afirma cristão. Este tipo de teologia faz a Igreja cair num descrédito em relação a sociedade e limita a reflexão e atuação da Igreja à "sacristia"; teologia sem influxo algum na sociedade e na cultura.

Este tipo de teologia tem seu início na Idade Média com a escolástica. Neste período houve a ruptura entre espiritualidade e teologia, nas palavras de Von Balthasar: teologia como ossadura sem carne e espiritualidade como carne sem ossos, período em que na história da Igreja houve muitos teólogos porém poucos santos. ${ }^{12}$ A partir de então a teologia foi sendo construída nesta ruptura com a experiência de fé que poderia até provocar admiração por sua construção na exatidão de termos e conceitos, no entanto, não despertava nos fiéis o desejo da experiência com Deus. ${ }^{13}$

$\mathrm{Na}$ origem da teologia cristã, no entanto, a experiência com o Deus revelado em Jesus Cristo e a comunicação da mesma é fundamental. ${ }^{14}$ Os Evangelhos e o todo o Novo Testamento são experiências de fé das primeiras comunidades cristãs. Experiências refletidas e escritas para que pudessem despertar novos corações apaixonados por Deus. Experiências que tem um fundo comum que é a experiência com o Ressuscitado, mas, que realizadas em diferentes contextos e por pessoas/comunidades diversas, enriquece a Igreja com diversas teologias já no seu começo. Há no Novo Testamento teologias suscitadas pelo revelar-se divino manifesto nas mais diversas situações de vida nas quais a mensagem de salvação foi acolhida e transmitida, experiência fonte das posteriores experiências com o Ressuscitado condensado como testemunho escriturístico.

Um período posterior é a época Patrística. Trata-se do rico período teológico da Igreja nos quais os Padres através de uma linguagem simbólica, sempre abertos ao Advento divino, buscavam comunicar a experiência de Deus com a finalidade de suscitarem novas experiências. Período em que o tesouro da Palavra de Deus é saboreado na vida cotidiana e unida aos sacramentos fortalece a vida dos cristãos. A teologia parte da experiência de Deus realizada no cotidiano de forma especial através da lectio divina e da celebração dos sacramentos. A teologia parte da fé celebrada e vivida pelas comunidades eclesiais.

\footnotetext{
${ }^{12}$ BALTHASAR, Hans Urs Von. Verbum Caro. Madrid: Ed. Cristianidad, 1971, pp. 235-254.

${ }^{13}$ MIRANDA, Mario de França. A Salvação de Jesus Cristo. p. 176.

${ }^{14}$ Tudo o que dissermos a seguir sobre a relação entre teologia e experiência pode ser melhor estudado em FORTE, Bruno. A teologia como companhia, memória e profecia. pp. 74-123.
} 
A unidade entre teologia e experiência é rompida com o período posterior aos Padres, a escolástica. Nesta apresenta-se fortemente o desejo de transmitir de maneira fiel o dado recebido. Se acresce neste período a utilização do instrumental da lógica aristotélica que determinou a metodologia teológica neste momento. A teologia foi-se desenvolvendo segundo os padrões acadêmicos afastando-se da vida e problemas reais das pessoas, perdendo-se em disputas de linguagem acessíveis apenas a um pequeno grupo de intelectuais. Neste período acontece a separação entre Oriente e Ocidente no qual o Oriente ainda integra o Mistério revelado, celebrado e vivido enquanto no Ocidente esta unidade é perdida. Embora se perceba grandiosas obras elaboradas neste período como também o esforço de trazer a experiência da fé à intelectualidade e ainda o de se preservar o tesouro da Sagrada Escritura e dos Padres, neste período a experiência da fé foi cristalizada. Este tipo de teologia gerou por um lado uma reflexão áspera que não encantava nem suscitava a fé, e por outro, gerou uma piedade intimista e até mesmo alheios a fé.

Somente com o Vaticano II se recuperou a necessária articulação entre teologia e experiência cristã. Isto se deu de forma especial pela revalorização da Palavra de Deus e dos textos patrísticos como também pela renovação da liturgia, incentivadas dos movimentos bíblicos, patrístico e litúrgico respectivamente. A Igreja assim retomou a memória de Origem, a experiência fundante que motiva e sustenta a fé. Percebe-se ainda a revalorização do sujeito que faz esta experiência: A Igreja, enquanto comunhão de fiéis, é que faz a experiência de Deus e não apenas um grupo seleto. Todos os cristãos são chamados a um encontro pessoal com Cristo e convocados por Ele a tornarem-se no mundo mensageiros e propiciadores de novos encontros com o Deus vivo. A cada um a experiência salvífica torna-se acessível no cotidiano de sua existência, e desta forma a vida humana é trazida novamente para o seio da teologia. A redescoberta da índole escatológica da Igreja a faz perceber-se no tempo não como detentora de um conhecimento absoluto de Deus, mas antes percebe-se como serva, como sacramento da ação de misericordiosa de Deus no mundo, possibilitando a cada um na sua existência relacionar-se com a Trindade Santa da qual ela é proveniente, na qual vive e para a qual se encaminha. Percebe-se como peregrina e compreende que não pode de maneira alguma dar uma palavra sobre Deus de modo a aprisioná-lo em conceitos.

Nesta simples abordagem daquilo que podemos chamar um resumo da trajetória histórica entre teologia e experiência, verifica-se a necessidade de 
se repensar a teologia a partir de seu elemento chave: a experiência com o Deus da salvação, de percebermos como é possível a cada ser humano a experiência de Deus.

\section{A experiência de Deus como fundamento da teologia}

O papa Bento XVI em sua primeira carta encíclica afirma: “Ao início do ser cristão, não há uma decisão ética ou uma grande idéia, mas o encontro com um acontecimento, com uma Pessoa que dá à vida um novo horizonte e, dessa forma, o rumo decisivo." ${ }^{15}$ Se evidencia neste sentido que o tornar-se cristão não se dá a partir de uma reflexão intelectual mas a partir de um verdadeiro encontro que envolve a totalidade da existência, de uma experiência realizada com Cristo que dá ao ser humano o sentido de sua existência, a visão e a valoração de seu mundo e neste sentido todas as decisões da vida. ${ }^{16}$ Trata-se da atitude de fé, de abertura a Presença de Deus em Jesus Cristo. A experiência de Deus necessita da fé. O ser humano não reduz Deus a fé, no entanto só realiza a experiência de Deus mediante ela. Inúmeros se encontraram com Jesus de Nazaré, porém nem todos fizeram um encontro, na fé, com Jesus abrindo-se a sua ação e reconhecendo-o como Salvador. A experiência de Deus que tratamos aqui necessita da atitude de fé.

A experiência que o ser humano faz de Deus é experiência de salvação. Encontro com o Deus amoroso e misericordioso que não é fruto de nossa subjetividade, mas algo que se esbarra a nós, dotado de autonomia, que nos surpreende e inquieta. ${ }^{17}$ A experiência de Deus é acolhida da autocomunicação de Deus, da livre e amorosa vontade e iniciativa de Deus de se relacionar conosco. Esta autocomunicação livre e amorosa, segundo Rahner, não vem a nós como algo de fora, como se fosse uma revelação na qual Deus falasse algo de si. Trata-se antes do mistério amoroso de Deus que faz-se presente ao ser humano a partir da própria estrutura transcendental deste, não como algo, como uma característica de Deus perceptível pelo ser humano, mas como Deus mesmo vindo ao seu encontro. ${ }^{18}$ É Deus que vem ao ser humano enquanto este tem em si mesmo a possibilidade desta autocomunicação divina, enquanto é

\footnotetext{
${ }^{15}$ BENTO XVI, papa. Carta encíclica Deus caritas est. São Paulo: Paulinas, 2006. n.1.

${ }^{16}$ CORETH, Emerich. Deus no pensamento filosófico. São Paulo: Ed. Loyola, 2009, p. 388.

${ }^{17}$ MIRANDA, Mario de França. Inculturação da fé. p. 63.

${ }^{18}$ RAHNER, Karl. Curso Fundamental da fé: introdução ao conceito de cristianismo. São Paulo: Paulus, 2004. p. 147.
} 
ser de transcendência. Neste encontro amoroso com Deus, o ser humano faz experiência daquilo que Deus é em si mesmo, pois se encontra com o próprio Deus, uma vez que aquele que se autocomunica é ao mesmo tempo doador e dom. Aquele que dá, não dá algo, mas dá-se si mesmo ao ser humano.

Enquanto ser de autotranscendência, o ser humano pode se relacionar com o Mistério. Esta possibilidade, que diz respeito a todos e a cada um dos homens e mulheres é designado por Rahner como "existencial sobrenatural". Trata-se da abertura do ser humano ao mistério que constitui o seu próprio ser e que o permite realizar-se enquanto pessoa. Neste sentido o mistério insondável que é Deus não é algo estranho ao ser humano mas a "experiência de que este mistério santo é proximidade acolhedora, a intimidade que perdoa, abrigo na fuga à estranheza vazia e ameaçadora de sua própria vida". ${ }^{19} \mathrm{E}$ a experiência por sua vez, com este "distante-próximo" por não ser algo de extraordinário, estranho a existência humana, ocorre nas coisas mais simples da vida, nas experiências que podem ser atemáticas e "arreligiosas". ${ }^{20}$ Aqui temos uma grande contribuição do autor em relação a espiritualidade. Viver e fomentar a espiritualidade neste sentido não está reduzida a alguns momentos convencionalmente tidos como religiosos, mas trata-se do acolhimento do mistério realizado no cotidiano da vida, experimentado sem ritualismos ou formalidades, sem com isto negar a possibilidade da experiência no rito.

Devemos ter presente contudo que a autocomunicação divina não se permite ser apreendida pelo ser humano como uma realidade categorial. Deus é aquele que "não permite que dele se disponha, mas que é a instância infinita e muda, que dispõe de nós no momento e todas as vezes que começamos a dispor de alguma coisa. ${ }^{21}$ Deus sendo transcendente, não será jamais capturável por nós, mas será sempre o Outro que nossa consciência e linguagem não dá conta. O que chamamos de experiência de Deus é mais propriamente uma experiência de sua ação misteriosa e misericordiosa. Nunca significaria que possamos perceber imeditamente a Deus em si mesmo em sua realidade absoluta e infinita, que ultrapassa as possibilidades humanas. Significa reconhecermos sua atuação em nós e por nós, que nos coloca numa relação pessoal com Ele que dá nova significação e orientação para nossas vidas. ${ }^{22}$ Trata-se de

\footnotetext{
${ }^{19}$ Ibid., p. 163.

${ }^{20}$ Ibid., 164; Exemplos desta experiência de Deus realizado no cotidiano da existência pode ser visto em RAHNER, Karl. Experiencia Del Espíritu. Madri: Narcea, 1977. pp. 47-53.

${ }^{21}$ RAHNER, Karl. O dogma repensado., p. 181.

${ }^{22}$ Cf. CORETH, Emerich. op. cit., p. 444.
} 
uma abertura ao horizonte último, inalcançável para o qual estamos estruturalmente voltados.

A experiência de Deus é neste sentido é o acontecimento significativo que configura a existência da pessoa, colocando-a em um novo horizonte e rumo, que na teologia comumente chamamos de conversão. A partir da experiência de Deus a pessoa delineia a sua vida, reconfigurando-a a partir deste encontro e em vista do encontro definitivo com Ele. Toda a realidade humana não é somente interpretada mas também experimentada a partir de Deus. Deus torna-se o decisivo e aquele que dá o sentido para a vida humana. Como Pedro, neste encontro podemos dizer: "Senhor, a quem iremos? Tens palavras de vida eterna e nós cremos e reconhecemos que tu és o Santo de Deus" (Jo 6,68). Em Cristo encontramos a verdadeira vida e o sentido verdadeiro desta.

Desta forma verifica-se que a questão da experiência está na base do tornar-se cristão e está presente em todos os momentos do cristianismo embora não tematizada. $\mathrm{O}$ inicio do cristianismo dá-se na experiencia de encontro com o Deus revelado em Jesus Cristo. Nesta experiência que fazemos com Deus está a base segura para o discurso sobre Deus. A teologia necessariamente está ancorada na experiencia que o ser humano faz de Deus, caso contrario poderia cair no risco de imaginá-lo erradamente, apresentar um Deus fruto de nossa imaginação e desejo. ${ }^{23}$

A teologia trata-se de uma tematização da experiência que lhe é anterior. Esta tematização pode ser compreendida e expressa de forma correta ou incorreta ainda que seja uma tentativa de expor uma verdadeira experiencia de Deus. É na experiência que a elaboração teológica surge, se desenvolve e recebe sua validação. E ainda que seja tematizada de forma correta será sempre insuficiente para expressar em conceitos a experiência fundante de Deus. Neste sentido é que Bruno Forte apresenta a necessidade da teologia perceber-se como serva apontando o Mistério e não o delimitando: "Desta teologia se requer que fale de Deus como serva humilde e não como senhora, que tenda a ele como peregrina rumo à luz, guiada pela estrela da redenção aparecida na noite do tempo, sem seduções de completude e de posse." ${ }^{24}$ Por mais que a teologia se esforce em dar uma palavra sobre Deus ela deverá ter sempre claro que esta palavra é limitada e que de forma alguma abarca aquilo que Deus é de fato. Ao mesmo tempo que Deus se revela, ou seja, dá-se a nós para que possamos experimentar o seu amor e sua gratuidade

\footnotetext{
${ }^{23}$ MIRANDA, Mario de França. Inculturação da fé. p. 71.
}

${ }^{24}$ FORTE, Bruno. op. cit., p. 26. 
ele continua aquele que se vela, é sempre o Outro a ser encontrado, o qual a teologia nutrida de vida de fé, busca a face e "tendo-o encontrado, não pára de buscá-lo, porque o seu ocultamento suscita o desejo de encontrá-lo e a sua imensidade, o de buscá-lo ainda mais" ${ }^{\prime 25}$. Encontrar-se com Deus, suscita neste sentido novos encontros com Ele, o desejo de incessantemente buscá-lo e enamorá-lo cada vez mais.

\section{Experiência mistagógica: razão de ser da teologia}

Ao perceber o seu limite de dizer uma palavra definitiva do Mistério, a teologia percebe seu caráter de narratividade. Ela é a narração do amor de Deus comunicado a nós em Jesus Cristo. Assume a atitude de humildade diante do Mistério que lhe é acessível na experiência não porém capturável, permanecendo o "Deus escondido". Ela "reaprende a falar de Deus narrando o amor: narra a história do amor do Pai e do Filho e do Espírito Santo, entre si e para com o mundo, tal como se manifestou no evento pascal a fim de fazê-la comunicativa e contagiosa a inumeráveis e humildes histórias dos homens, marcadas pela fadiga de amar". ${ }^{26}$ Se a história atual da humanidade é marcada pela força do individualismo pragmático e narcisista (DA 51) no qual a experiência do amor ao próximo parece como discurso até razoável no entanto sem condição de aplicabilidade, a experiência do amor de Deus, do próprio Deus que vem ao nosso encontro, nos faz perceber que o amor é possível e se faz realidade em Jesus Cristo para que também possamos nós fazermos esta experiência do amor: "Nisto se manifestou o amor de Deus por nós: Deus enviou o seu Filho único ao mundo para que vivamos por ele. Nisto consiste o amor: não fomos nós que amamos a Deus mas foi ele quem nos amou e enviou-nos o seu Filho como expiação pelos nossos pecados" (cf. 1 Jo 4, 9-10). Deus é o pioneiro no amor. Ele é o primeiro a amar convidando-nos a acolhermos o seu amor e também a o experimentamos na vida cotidiana. A experiência do amor de Deus nos faz acreditar no amor.

Fazer teologia, ou seja, narrar a experiência de Deus em nós através de Jesus Cristo pela ação do Espírito Santo não tem como finalidade o mero conhecimento intelectual de terceiros sobre tal, mas antes, a comunicação desta experiência para que outros também possam realizá-las em suas vidas. Narrando o Amor a teologia procura tornar a experiência do amor de Deus acessível a toda

\footnotetext{
${ }^{25}$ Ibid., p. 59.

${ }^{26}$ Ibid., p. 52.
} 
e qualquer pessoa, que uma vez imersa nesta, é envolvida por ela de modo a viver segundo a amorosidade de Deus. Experimentando o amor eterno, envolvido e acolhido pela história trinitária de amor, o ser humano pode construir em sua vida histórias de amor. ${ }^{27} \mathrm{O}$ amor de Deus capacita o ser humano para as experiências diárias de amor seja para com Ele seja para com os outros.

Cabe a teologia neste sentido ouvir também para si o convite de Jesus: "Ide, portanto, e fazei que todas as nações se tornem discípulos, batizando-as em nome do Pai, do Filho e do Espírito Santo" (Mt 28,19). Possibilitar que todos tenham o conhecimento de Cristo e possam ter uma experiência com Ele tornando-se discípulos Dele não por coação mas como proposta salvífica é a missão da teologia. Ela deve dar as razões de sua esperança (cf. 1Pd 3,15) aos homens e mulheres de hoje para que tenham condições de fazerem eles mesmo a experiência do Mistério amoroso de Deus.

Aquilo a que chamamos de "formulações dogmáticas" tratam-se da experiência de Deus realizada pela Igreja e expressa nas diferentes épocas e contextos. Estas devem possuir sempre o seu aspecto de meio e não fim. Contribuem para com a Igreja na sua missão de ser sacramento de Cristo para o mundo (LG 1), ou seja, de o apresentar sendo veículo para tal encontro. As formulações dogmáticas são meio de tornar a experiência salvífica acessível em cada momento histórico. Para tal devem ser expressas de modo inteligível em cada momento histórico com o contexto que lhe é próprio, não caindo na tentação de se aprisionar em expressões que no passado tiveram a sua razão de ser mas que nos dias atuais não conseguem mais comunicar, muito menos tornar acessível a experiência. "Formulações de fé deveriam neste sentido ter o caráter mistagógico, não limitando a refletir a expressão correta da verdade salvífica (ortodoxia), mas também provindo de e conduzindo a mesma verdade vivida (ortopraxia) na comunidade eclesial. ${ }^{28}$ Enfim, mostra-se latente a necessidade de se repensar a teologia buscando novos conceitos e nova linguagem que possa dizer algo para o ser humano de hoje, que seja inteligível para ele e que o motive a fazer tal experiência. A teologia "apresenta-se, pois a um só tempo como o movimento que vai da experiência à palavra (...) e o movimento inverso da palavra à experiência, lá onde no silêncio da escuta ressoa mais pura a Palavra para encontrar as palavras e verificá-las, subvertê-las, nutri-las, e sempre manter aberto o caminho do êxodo à novidade e ao excesso do

\footnotetext{
${ }^{27}$ Ibid., p. 53.

${ }^{28}$ MIRANDA, Mario de França. Inculturação da fé. p. 74.
} 
advento". ${ }^{29}$ Provém da experiência de Deus, do apaixonar-se por Ele encontrando nele o sentido da vida e buscando exprimir esta alegria em palavras que por sua vez motivadoras a abertura do ser humano a Deus, convite a este para que numa atitude humilde possa abrir-se a uma experiência que revela e possibilita a verdadeira vida. ${ }^{30} \mathrm{O}$ labor teológico é a tentativa de exprimir limitadamente a experiência da salvação realizada por nós afim de que ela possa ser também vivida por nossos contemporâneos.

Enfim, vemos a necessidade da teologia de repensar-se a si mesma para que possa ser veículo da experiência de Deus. Uma teologia abstrata, que desconsidera a concreta história humana com seus amores e desamores não realiza sua missão de levar a humanidade ao Amor. Cabe-nos, portanto, recomeçar a partir de Cristo, da experiência fundante, que inaugurou a Igreja tornando-a missionária nos tempos e contextos diversos para que esta experiência possa ter a força subversiva que lhe é própria, transformando a história humana em história de salvação possibilitando ao ser humano que faz a experiência a releitura de sua vida como também uma nova configuração da mesma. Elaborar uma teologia que toque ao coração e a vida das pessoas em todas as suas dimensões eis a vocação da teologia.

\section{Referências Bibliográficas}

BALTHASAR, Hans Urs Von. Verbum Caro. Madrid: Ed. Cristianidad, 1971.

BENTO XVI, Papa. Carta encíclica Deus caritas est. São Paulo: Paulinas, 2006. n.1.

CAPRA, F. O ponto de mutação. São Paulo: Cultriz.

CORETH, Emerich. Deus no pensamento filosófico. São Paulo: Ed. Loyola, 2009.

FORTE, Bruno. A teologia como companhia, memória e profecia. Introdução ao sentido e ao método da teologia como história. São Paulo: Paulinas, 1991.

_- A teologia como companhia, memória e profecia. .

\footnotetext{
${ }^{29}$ FORTE, Bruno. op. cit. p. 59.

${ }^{30}$ Aqui cabe a recordação do convite a humildade feito por Santo Agostinho para que o ser humano possa abrir-se a experiência da salvação: "Ó homens, até quando sereis duros de coração? Será possível que, depois que a vida desceu sobre a terra, não queiras subir e viver? Mas para onde subis, se já estais no alto, abrindo a boca contra o céu? Descei, a fim de subirdes para Deus, pois caístes elevando-vos contra ele!” AGOSTINHO, Santo. Confissões. São Paulo: Paulus, 1984. Liv IV, n. 12. pp. 100-101
} 
GUTIÉRREZ, Gustavo. Falar de Deus a partir do sofrimento do inocente: uma reflexão sobre o livro de Jó. Petrópolis, RJ: Vozes, 1987.

HERVIEU-LEGER, Danièle. O peregrino e o convertido: a religião em movimento. Petrópolis, RJ: Vozes, 2008.

MIRANDA, Mario de França. Inculturação da fé. São Paulo: Loyola, 2001. A Salvação de Jesus Cristo: a doutrina da graça. São Paulo: Edições Loyola, 2004.

RAHNER, Karl. O Cristão do Futuro. São Paulo: Cristã Novo Século, 2004.

Curso Fundamental da fé: introdução ao conceito de cristianismo. São Paulo: Paulus, 2004.

Experiencia Del Espíritu. Madri: Narcea, 1977.

O dogma repensado.

SCHILLEBEECKX, Edward. História humana: revelação de Deus. São Paulo: Paulus, 2003.

Renato da Silva Machado

Mestre em Teologia Sistemático-Pastoral pela PUC-Rio Vigário paroquial da Paróquia N. Sra . da Vitória - Barra da Tijuca/RJ e-mail: remadc@hotmail.com

Artigo Recebido em 22/08/2011 Artigo Aprovado em 25/11/2011 